\title{
Treatment of the Displaced Middle Third Clavicle Fracture with Pre Contoured Clavicular Locking Plate: Study in Border Guard Hospital, Pilkhana, Dhaka, Bangladesh
}

\author{
Shameem MAA ${ }^{1 *}$, Reza $\mathrm{H}^{2}$, Hossain $\mathrm{SZ}^{3}$, Alam $\mathrm{SAU}^{4}$, Siddiqui $\mathrm{EH}^{5}$
}

${ }^{1}$ M. A. A. Shameem, Assistant Professor, Orthopedics Department, Border Guard Hospital Dhaka, Bangladesh

${ }^{2}$ Md. Humayun Reza, Assistant Professor, Orthopedics Department, Shaheed M. Monsur Ali Medical College, Sirajganj, Bangladesh

${ }^{3}$ Syed Zakir Hossain, Assistant Professor, Orthopedics Department, Dhaka Medical College, Dhaka, Bangladesh

${ }^{4}$ Syed Asif Ul Alam, Assistant Professor, Orthopedics Department, Faridpur Medical College, Faridpur, Bangladesh

${ }^{5}$ Erfanul Huq Siddiqui, Medical Officer, Orthopedics Department, BSM Medical University, Dhaka, Bangladesh

Background: Till now treatment of displaced middle third clavicle fractures is highly controversial. Clavicle fracture is a very common fracture of human skeleton. Midshaft clavicle fractures accounts more than $80 \%$ among total clavicle fractures. Open reduction along with internal fixation with pre-contoured locking plate is a good treatment option for displaced middle third clavicle fracture. We have very few data regarding this issue. Aims $\&$ Objectives: The aim of this study was to evaluate the outcome of treatment procedure of displaced middle third clavicle fracture with pre-contoured locking plate. Materials \& Methods: This was a prospective observational study which was conducted on 50 patients in Border Guard Hospital, Dhaka, Bangladesh during the period from June 2017 to December 2019. All the participants had displaced middle third clavicle fracture and treated with pre-contoured locking plate. The study was approved by the ethical committee of the mentioned hospital. All necessary data were collected, processed, analyzed and disseminated by MS office and SPSS version 16 program as per need. Results: In this study as complications of this treatment procedure we found, the highest 5 patients suffered from dysesthesia. Then 2, 1, another 1 and 2 patients suffered from superficial infection, plate pullout, plate loosening and hardware irritation respectively. In analyzing the treatment duration for union we found the highest (48\%) number of cases taken 11-12 weeks for radiological union. Then $36 \%, 12 \%$ and $4 \%$ taken $9-10,>12$ and $<8$ weeks respectively. According to the Constant Murley Score (CMS) as final outcome we found maximum patients got 'Excellent' result which was $66 \%$ and the rest 34\% got 'Good' result. Conclusion: Comparatively open reduction and internal fixation with precontoured locking plate is a good option for displaced midshaft clavicle fracture. It ensures immediate pain relief, early return to work and prevents complications like non-union, mal-union and shoulder stiffness. It provides strong fixation due to locking between the screw and plate, and blood supply preservation due to minimal contact between plate and cortical bone. In this study the main indications for surgery were displacement, shortening and comminution.

Keywords: Middle third, Clavicle fracture, Locking plate, Open reduction, Clavicular.

Copyright $\odot 2020$ The Author(s): This is an open-access article distributed under the terms of the Creative Commons Attribution 4.0 International License (CC BY-NC 4.0) which permits unrestricted use, distribution, and reproduction in any medium for non-commercial use provided the original author and source are credited.

\section{INTRODUCTION}

Till now treatment of displaced middle third clavicle fractures is highly controversial. Clavicle fracture is a very common fracture of human skeleton. Midshaft clavicle fractures accounts more than $80 \%$ among total clavicle fractures. Open reduction along with internal fixation with pre-contoured locking plate is a good treatment option for displaced middle third clavicle fracture. We have very few data regarding this issue. There are various methods of operative fixation of midshaft clavicle fracture like intramedullary flexible nailing, screw fixation, recon plating and anatomical plating. Open reduction and plating is considered gold standard method for midshaft clavicle fracture [1]. The use of anatomical contoured clavicular locking plate is better option because the surgeon does not need to contour the plate which retains the mechanical strength of the plate and has less soft tissue related problems [2]. The precontoured plate has an added benefit of less hardware prominence which decreases the need of removal of implant after healing of fracture as compared to traditional plate [3]. Three types of surgical treatments are available, intramedullry devices such as K-wires, 
Steinman pins, Knowles pins cannulated screws; plates such as dynamic compression plate, reconstruction plates or locking compression plates and external fixators. Plate fixation has been advocated to be one of the options for treatment [4]. Low contact dynamic compression plates are strong but difficult to contour, thereby causing irritation of the soft tissue. On the other hand, reconstructed plates have the capacity to contour easily but they are not mechanically strong. A better option is the precontoured locking plates which provide immediate relief, stabilization and early mobilization, more so because they do not require further bending. They are also known to cause fewer soft tissue problems. Several studies have examined the safety and efficacy of primary open reduction and internal fixation for completely displaced midshaft clavicular fractures and have noted high union rate with a low complication rate [5]. In a large number of complex clavicle fractures a satisfactory outcome is possible with a low complication rate using a locked compression plate [6]. Primary internal fixation of displaced comminuted mid-shaft clavicular fractures leads to predictable and early return to function [7]. While the overwhelming majority of clavicle fractures are benign, associated life-threatening intrathoracic injuries are possible. Complications vary based on location of fracture [8]. Fracture of the clavicle is associated with delayed union or nonunion [9], brachial plexus compression resulting from hypertrophic callus formation, compression or laceration of the great vessels, trachea, or esophagus, injuries to the neurovascular bundle and the pleural dome, poor cosmetic appearance, pneumothorax and intra-thoracic injury. There are various plates including Sherman plates, Dynamic compression plates and Semi tubular plates. Among them, a reconstruction plate and anatomical locking compression plate are widely used. We have conducted this study to gain a deeper understanding of results and complications associated with this procedure to evaluate the functional outcome after fixation of displaced clavicular fractures with locking compression plate.

\section{OBJECTIVES \\ General Objective}

- To evaluate the treatment of displaced middle third clavicle fracture with pre contoured clavicular locking plate.
- To observe the clinical findings among the patients with displaced middle third clavicle fracture.

- To observe the duration of treatment procedure for radiological union of participants.

- To assess the complications of treatment of clavicle fractures with locking plate.

\section{Methodology \& Materials}

This was a prospective observational study which was conducted on 50 patients in Border Guard Hospital, Dhaka, Bangladesh during the period from June 2017 to December 2019. All the participants had displaced middle third clavicle fracture and treated with pre-contoured locking plate. The study was approved by the ethical committee of the mentioned hospital. All patients were treated with open reduction and internal fixation of the clavicle with a pre-contoured superior clavicle locking plate. According to the inclusion criteria of the study, patients of age more than 19 years, either sex, comminuted, displaced (Larger than $2 \mathrm{~cm}$ ), shortening (Larger than $2 \mathrm{~cm}$ ), segmental fractures, fractures with tenting of skin were included. On the other hand, according to the exclusion criteria, patients with associated injuries of the shoulder girdle open fractures pathological fractures established non-union from previous fracture non-compliant or substance abusers were excluded. The implant applied in all our patients was a pre-contoured $3.5 \mathrm{~mm}$ superior clavicle locking compression plate. Another set of $2.7 \mathrm{~mm} \mathrm{lag}$ screws was always kept ready, in order to lag any unstable butterfly fragment (s), if the need arose. The proper written informed consent was received from all the patients for their participation in this study. Proper history of the patient was taken, ascertaining the mode of injury, with particular emphasis placed on ruling out injuries to other areas. AP views of the involved shoulder and $20^{\circ}$ cranial views were taken, so as to have a full visualization of the clavicle. All the surgeries were performed under general anaesthesia. The patients were positioned in either the supine, with the head and neck tilted away from the surgical site with a bump placed behind the scapula to aid in reduction. The arm was prepared in the field to allow for traction and manipulation to assist in the reduction. Pre-operative intra-venous antibiotic was given to the patient, at least 30 minutes before making the skin incision. A direct skin insicion was made over the clavicle. The subcutaneous tissue and platysma muscle were kept together as one layer and extensively mobilized, especially proximally and distally. Sharp dissection was taken down to the bone, with care to identify, and if possible, preserve the cutaneous supraclavicular nerves. When deemed necessary, they were sacrificed.

\section{Specific Objective}




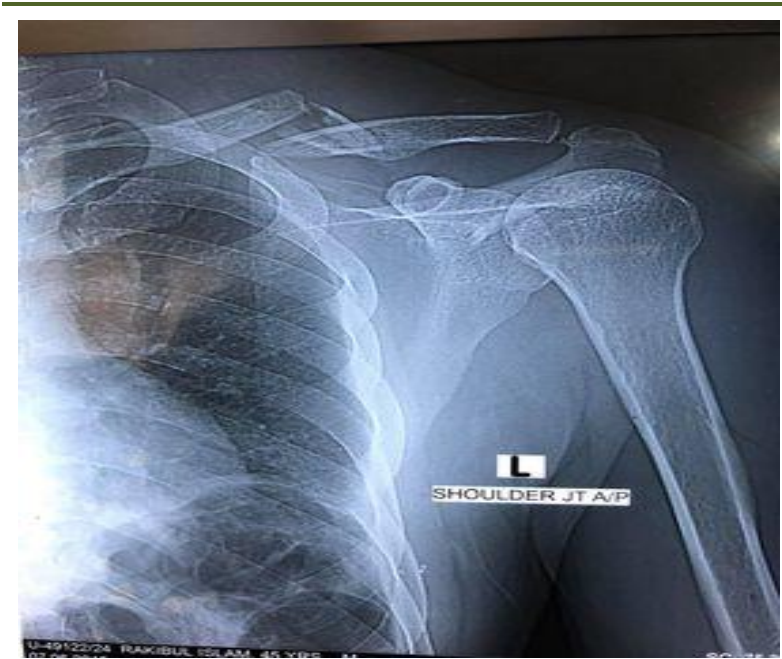

Image-I: Photograph of pre-operative stage

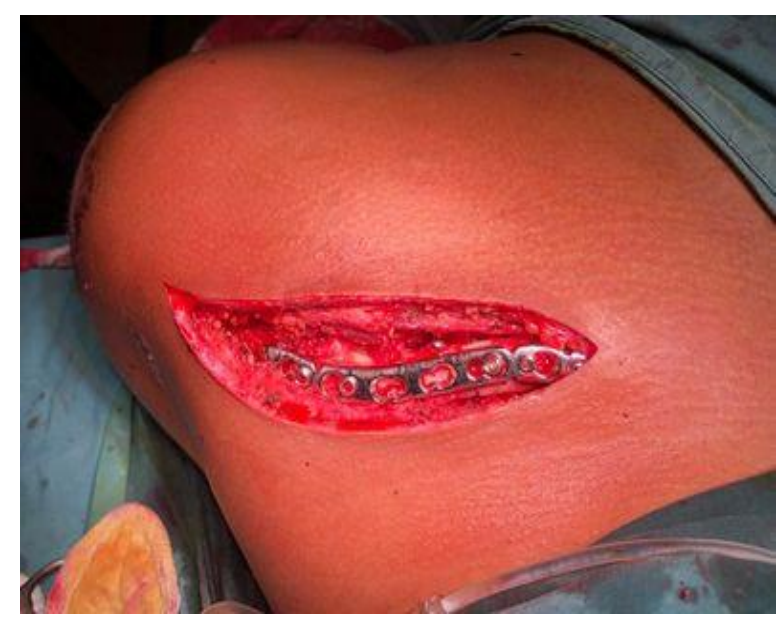

Image-II: Photograph of per-operative stage

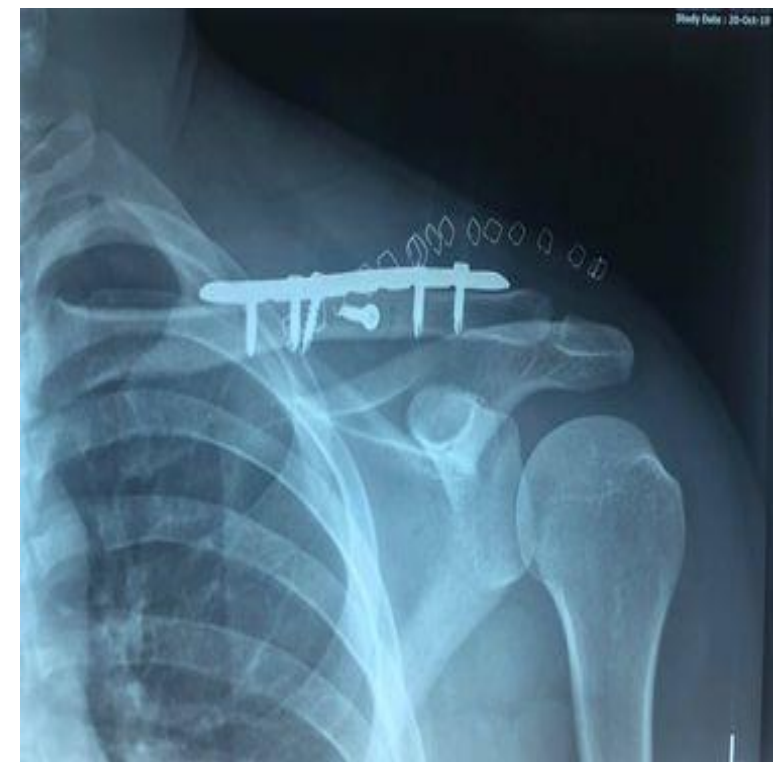

Image-III: Photograph of post-operative stage

The myofascial layer over the clavicle was incised and elevated in one continuous layer. Comminuted fragments, especially the often seen antero-superior fragment was teased back into position, as much as possible, maintaining its soft tissue attachments. At least 4 cortices on either side of the fracture were held by cortical screws. Once plating was completed, the fascia was repaired over the plate. Skin incision was closed. Antiseptic dressing was applied, and the arm was rested in an arm sling. Then the patient was kept in the post-operative recovery ward, under observation. Vitals were monitored pendulum exercises of the shoulder were started, with the arm still rested in the arm sling. The patient was discharged on the second post-operative day, and intravenous antibiotics were stopped on the same day. All patients were followed up at 2 weeks, 6 weeks, 12 weeks, and 6 months: as per need. All necessary data were collected, processed, analyzed and disseminated by MS office and SPSS version 16 program as per need.

\section{RESUlT}

In this study among 50 study people the highest number of participants were from 31-40 years' age group which was $44 \%$. Then $36 \%, 14 \%$ and $6 \%$ were from 20-30, $41-50$ and $>50$ years' age groups respectively. The mean $( \pm \mathrm{SD})$ age of the participants was $37.50 \pm 3.61$ years. In this study $96 \% \quad(n=48)$ participants were male whereas $4 \%(n=2)$ were female. So male were dominating in number. In defining the side of fractures we observed, in $44 \%$ fractures right side and in $56 \%$ fractures left side were involved. In analyzing the causes of injury we found, $48 \% 36 \%$, and $16 \%$ causes of injuries were RTA, fall from height and sport injury respectively. In this study as complications of this treatment procedure we found, the highest 7 patients suffered from dysesthesia. Then 4 , another 4,3 and 2 patients suffered from superficial infection, plate pullout, and plate loosening and hardware irritation respectively. In this current study one patient refractured the clavicle with the plate in situ after 7 weeks due to fall with an out stretched hand. He was treated conservatively and fracture united after 18 weeks. Almost all patients returned back to work after an average sick leave of 10 weeks. In analyzing the treatment duration for union we found the highest (48\%) number of cases taken 11-12 weeks for radiological union. Then $36 \%, 12 \%$ and $4 \%$ taken $9-10$, $>12$ and $<8$ weeks respectively. According to the Constant Murley Score (CMS) as final outcome we found maximum patients got 'Excellent' result which was $66 \%$ and the rest $34 \%$ got 'Good' result.

Table-I: Age distribution of participants $(\mathrm{N}=50)$

\begin{tabular}{|c|c|c|}
\hline Age (Years) & $\mathbf{n}$ & $\boldsymbol{\%}$ \\
\hline $20-30$ & 18 & $36 \%$ \\
\hline $31-40$ & 22 & $44 \%$ \\
\hline $41-50$ & 7 & $14 \%$ \\
\hline$>50$ & 3 & $6 \%$ \\
\hline
\end{tabular}




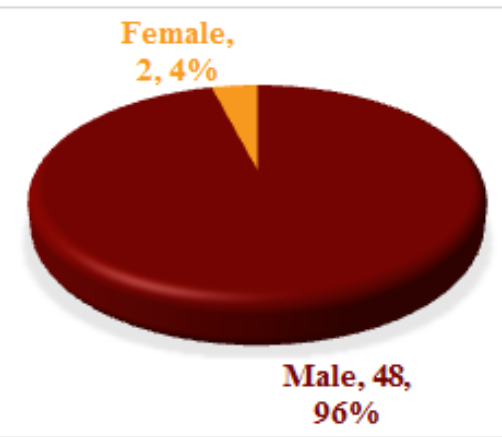

Fig-I: Gender distribution of participants $(\mathrm{N}=50)$

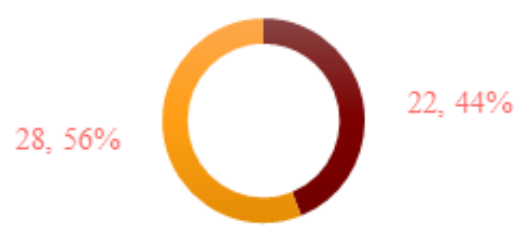

- Right $\mathbf{m}$ Left

Fig-II: Side involvement of fractures among participants $(\mathbf{N}=\mathbf{5 0})$

Table-II: Causes of injury among participants

\begin{tabular}{|l|c|c|}
\multicolumn{1}{|c|}{ Causes } & $\mathrm{n}$ & $\%$ \\
\hline RTA & 24 & 48 \\
\hline Fall from height & 18 & 36 \\
\hline Sport injury & 8 & 16 \\
\hline
\end{tabular}

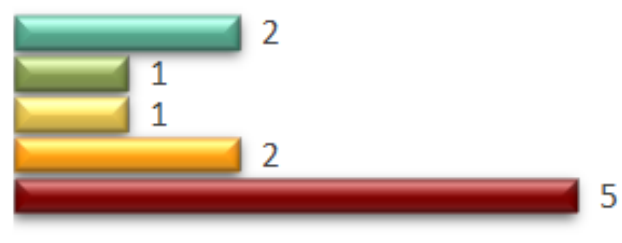

घHardware irritation $\boldsymbol{\Delta}$ Plate loosening

$\square$ Plate pullout $\square$ Superficial infection

Dysesthesia

Fig-III: Complications among participants $(\mathbf{N}=\mathbf{5 0})$

Table-III: Treatment duration for radiological union of participants $(\mathbf{N}=50)$

\begin{tabular}{|l|c|c|}
\hline \multicolumn{1}{|c|}{ Duration } & n & \% \\
\hline$<8$ Weeks & 2 & $4 \%$ \\
\hline 9-10 Weeks & 18 & $36 \%$ \\
\hline $11-12$ Weeks & 24 & $48 \%$ \\
\hline$>12$ Weeks & 6 & $12 \%$ \\
\hline
\end{tabular}

Table-IV: Final outcome of participants according to $\mathrm{CMS}(\mathrm{N}=50)$

\begin{tabular}{|l|c|c|}
\hline Score & $\mathbf{n}$ & $\mathbf{\%}$ \\
\hline Excellent & 33 & $66 \%$ \\
\hline Good & 17 & $34 \%$ \\
\hline
\end{tabular}

\section{DiSCUSSION}

The aim of this study was to evaluate the outcome of treatment procedure of displaced middle third clavicle fracture with pre-contoured locking plate. Basing on the results by Neer and Rowe $[10,11]$ in the 60 's, for many years it was thought that, barring a limited number of exceptions, a non-operative treatment for mid-shaft displaced clavicle fractures always produced good results. As a matter of fact, these two studies are subjected to relevant criticism: firstly, they include in their cases record a high number of teenagers - whose treatment is usually non-operative and secondly evaluation tests for upper limb functioning such as Dash and Constant score were not available. Hill [12] was the first to carry out an extensive review of patients treated with figure-of-eight bandages for displaced middlethird clavicle fractures discovering up to $31 \%$ of patients reporting dissatisfaction of the outcome. From a biomechanical point of view it should be noted that during elevation the clavicle performs a triple movement of: rotation on its own axis, posterior inclination, and upward inclination [13], contributing to scapulo-thoracic articulation movement and consequently to the shoulder girdle movement. Moreover the clavicle is tasked of the transmission of the force from the trunk to the upper arms and consequently with giving stability and strength to overhead movements. Lazarides[14] and Ledger [15] in their biomechanical studies have showed how clavicle nonunion with shortening over $2 \mathrm{~cm}$ can determine a significant reduction of leverage and subacromial space. A radiological study carried out by Andhemar[16] has shown in these cases an increment of the sternoclavicular angle, possible cause of a malpositioning of the scapula on the chest wall. All these alterations can cause pain and a strength reduction of overhead movements in clavicle fractures mal-unions, as shown by a study of McKee in 2003[17]. The surgical treatment of such lesions can be performed with several surgical techniques: the most widely employed are the intramedullary nail and the plate with screws. Several biomechanical studies have shown the superiority of the plate over the nail [18]. There were specific indications like displacement, with or without comminuted middle third clavicle fracture (Robinson Type-2B1, 2B2). The present study of patients with comminuted midshaft clavicle fractures is compared with Bostman et al. [19] study which treated middle third clavicle fractures. In that study totally 103 patients were treated by early open reduction and internal fixation with plate and screws. It was also compared with Cho et al. [20] study where 41 patients with a clavicle midshaft fracture were treated by internal 
fixation with a reconstruction plate (19 patients) or reconstruction LCP (22patients). In our prospective study 48 patients were male whereas only 2 patients were female. Noted that, our hospital is a special hospital which provides treatment to BGB (Border Guard Bangladesh: A paramilitary force under the Ministry of Home Affairs of Bangladesh) members only and most of the BGB members are male. In Bostman et al. [19] series also commonly males are affected 76 Patients (73.79\%) compared to females 27 Patients (26.21\%). In Cho et al. [20] study, the reconstruction plate group that 12 male and 7 female Patients and in the locking compression plate group it was 17 male and 5 patients were female. So male were dominating in number in all the studies. In this present study, Robinson Type-2 B1 (Displaced with simple or butterfly fragment) were more common. In Bostman et al. [19] study also Robinson type-2B1 was common in 81 patients $(78.64 \%)$. Robinson type-2 B2 occurred only in 22 patients $(21.36 \%)$. In Cho et al. [20] study, in reconstruction plate group there were 7 Patients with B1 type and 12 Patients with B2 type and that of the locking compression group had 9 B1 type and 13 B2type. In our study all patients were operated within 4 days of admission. In Bostman et al. [19] study all the patients were operated within 3 days of injury. In Cho et al. [20] study, the reconstruction plate group was operated by 4 days and that of locking compression plate was 9 days. In analyzing the treatment duration for union we found the highest $(38 \%)$ number of cases taken 11-12 weeks for radiological union. Then $34 \%$, $16 \%$ and $12 \%$ taken $9-10,<8$ and $>12$ weeks respectively. There was no non-union. In Cho et al. [20] study, bony union for reconstruction plate was 14.6 weeks and that of locking compression plate was 13.2 weeks. In this study as complications of this treatment procedure we found, the highest 7 patients suffered from dysesthesia. Then 4, another 4, 3 and 2 patients suffered from superficial infection, plate pullout, plate loosening and hardware irritation respectively. Both Bostman et al. and Cho et al. [20] didn't have any major complications either. Plate loosening occurred in only 1 patient at the end of 4 weeks postoperatively. The cause in this patient was also due to noncompliance with the post-operative protocol. The patient went for working in the field before the fracture union. With further advice of not to lift heavy weights in the affected limb clavicle fracture went to unite in mal position at end of 12 weeks and no reoperation was performed for this. In Bostman et al.[19] study 7 patients $(6.80 \%)$ had implant loosening. In all the patients loosening occurred at 6 postoperative weeks. Mal-union of varying degree followed in all of these patients and no reoperations were performed. In Cho et al. study [20], only there construction group that plate loosening in 3 patients $(15.8 \%)$. We had not any case of delayed union at al. But in Bostman et al. [19] study delayed union occurred in 3 Patients (2.91\%). According to the Constant Murley Score (CMS) as final outcome we found maximum patients got 'Excellent' result which was $66 \%$ and the rest $34 \%$ got 'Good' result. This outcome was better than other studies we had studied.

\section{Limitations of the Study}

This was a single centered study with small size sample. So, study results may not be reflect the exact scenario of the whole country.

\section{CONCLUSION AND RECOMMENDATIONS}

Comparatively open reduction and internal fixation with pre-contoured locking plate is a good option for displaced midshaft clavicle fracture. It ensures immediate pain relief, early return to work and prevents complications like non-union, mal-union and shoulder stiffness. It provides strong fixation due to locking between the screw and plate, and blood supply preservation due to minimal contact between plate and cortical bone. In this study the main indications for surgery were displacement, shortening and comminution. The findings of this study may be helpful in further similar studies and in treatment procedure of displaced middle third clavicle fracture. But this was a single centered study with a small sized sample. So the findings of this study may not reflect the exact scenario of the whole country. For getting more specific findings we would like to recommend for conducting more studies regarding the same issue with larger sized sample.

\section{REFERENCES}

1. Zlowodzki M, Zelle BA, Cole PA and McKee MD. Treatment of acute midshaft clavicle fractures: systematic review of 2144 fractures: on behalf of the Evidence-Based Orthopaedic Trauma Working Group. J Orthop Trauma. 2005;19: 504-507.

2. Allmann FL. Fractures and Ligamentous Injuries of the Clavicle and Its articulation. J Bone Joint Surg [Am] 1967; 49:774-784.

3. VanBeek C, Boselli KJ, Cadet ER, Ahmad CS and Levine WN. Precontoured plating of clavicle fractures: decreased hardware-related complications? Clin Orthop Relat Res. 2011;469(12):3337-3343.

4. Ring D, Jupiter JB, Miller ME, Ada JR. Injuries to the shoulder girdle: part II. Fractures of the clavicle. In: Browner BD, Jupiter JB, Levine AM, Trafton PG, (eds). Skeletal trauma. Volume 2. Philadelphia: WB Saunders; 1998: 1670.

5. Holbrook TL. The Frequency of Occurrence, Impact, and Cost of Selected Musculoskeletal Conditions in the United States. Chicago, Ill.: American Academy of Orthopaedic Surgeons; 1984. 
6. Robinson CM. Fractures of the clavicle in the adult. Epidemiology and classification. J Bone Joint Surg Br. 1998; 80:476-84.

7. Neer CS. Nonunion of the clavicle. JAMA. 1960; 172:1006-11.

8. Hill JM, McGuire MH, Crosby L. Closed treatment of displaced middle-third fractures of the clavicle gives poor results. J Bone Joint Surg (Br). 1997; 79:5.

9. Boehme D, Curtis RJ, DeHaan JT. Nonunion of fractures of the mid-shaft clavicle. J Bone Joint Surg (Am). 1991; 73:1219-26.

10. Neer C S. Nonunion of the clavicle. JAMA. 1960; 172(10): 1006-11.

11. Rowe C R. An atlas of anatomy and treatment of mid-clavicular fractures. Clin Orthop Related Res. 1968; 58:29-42.

12. Hill J M, McGuire MH, Crosby LA. Closed treatment of displaced middle-third fractures of the clavicle gives poor results. J Bone Joint Surg [Br]. 1997; 79-B: 537-9.

13. Smekal V, Deml C, Iremberger A. Length determination in midshaft clavicle fractures: validation of measurement. J Orthop Trauma. 2008; 22: 458-462.

14. Lazarides S, Zafiropoulos G, Conservative treatment of fractures at the middle third of the clavicle: the relevance of shortening and clinical outcome. J Shoulder Elbow Surg. 2006; 15(2): 191-4.

15. Ledger M, Leeks N, Ackland T. Short malunions of the clavicle: an anatomic and functional study. J Shoulder Elbow Surg. 2005; 14:349-354.

16. Andermahr J, Jubel A, Elsner A. Malunion of the clavicle causes significant; 28 glenoid malposition: a quantitative anatomic investigation. Surg Radiol Anat. 2006; 28:447456.

17. McKee MD, Wild LM, Schemitsch EH Midshaft malunions of the clavicle. J Bone Joint Surg [Am]. 2003; 85-A: 790-7.

18. Golish SR, Oliviero JA, Francke EI. A biomechanical study of plate versus intramedullary devices for midshaft clavicle fixation. J Orthop Surg Res. 2008; 3(28): 1-5.

19. Bostman O, Manninen M, Pihlajamaki $H$. Complications of plate fixation in fresh displaced mid clavicular fractures. J Trauma. 1997; 43:778-783.

20. Chul-Hyun Cho, Kwang-Soon Song, ByungWoo Min, Ki-Cheor Bae, Kyung-Jae Lee. Reconstruction Plate versus Reconstruction Locking Compression Plate for Clavicle Fractures. Clinics in Orthopedic Surgery. 2010: 2:154-159. 